\title{
Analysis of selected gaseous organic micro-pollutants in air by means of solid phase microextraction-gas chromatography-mass spectrometry. Calibration problems
}

\author{
J. Namieśnik, D. Gorlo, L. Wolska and B. Zygmunt \\ Department of Analytical Chemistry, Chemical Faculty \\ Technical University of Gdañsk (TUG), 80-956 Gdañsk, Poland
}

\begin{abstract}
In this work, problems related to calibration of solid phase microextraction (SPME) device were described. The effects of humidity and temperature on organic pollutants sampling from gaseous matrices on a $100 \mu \mathrm{m}$ PDMS coated SPME fiber were studied. Standard gaseous mixtures used in these studies were generated by the permeation method and humidified to known levels of relative humidity. The SPME-GC-MS based procedure was used to determine organic vapours (carbon tetrachloride, toluene, chlorobenzene, $p$-xylene and $n$-decane) in a laboratory air.
\end{abstract}

Key words. Solid phase microextraction — gas chromatography — calibration — volatile organic air pollutants - mass spectrometry.

\section{Introduction}

Due to possible health hazards many gaseous organic pollu tants must be determined in indoor (including workplace) and outdoor air at very low concentrations [1]. Final analysis, generally performed by gas chromatography (the most suitable technique in this case), usually must be preceded by isolation and enrichment of analytes of interest to a concentration determinable with acceptable accuracy and precision. This step is commonly based on dynamic analyte trapping on solid sorbents, passive dosimetry and denudation [2], which most often are laborious and time-consuming. Studies to modify existing analytical methodologies and also to develop new methods are constantly conducted.

Quite a new isolation and enrichment technique is the solid phase microextraction (SPME) developed by Pawliszyn et al. [3-6]. In this technique the analytes are sorbed by a small diameter fused silica fiber coated with a thin film of stationary phase and subsequently desorbed in a GC injector.

SPME combines analyte sampling, isolation and enrichment into one step; the analytes are desorbed from the fiber in an injection port and transferred directly to a chromatographic column for separation. To perform GC analysis, no modification of a standard gas chromatograph is needed. Being quite simple and convenient, SPME has found wide application in analysis of different organic pollutants, mainly in aqueous matrices and, to a lesser extent in analysis of gaseous samples. Using SPME in combination with GCECD, Chai et al. [7] obtained the detection limits of the order of ppt (parts per trillion, v/v) and relative standard deviations of $1-7 \%$ for volatile chlorinated hydrocarbons (VCHs) in air. Sample preparation time was quite short (c.a. $10 \mathrm{~min}$ ). With a fiber coated with graphitised carbon black (GCB) Mangani and Cenciarini [8] have determined volatile organic compounds (VOCs) in different air samples (air in an underground parking garage and in occupational environments) with good accuracy and precision. Chai and Pawliszyn [9] have developed an SPME based gas chromatographic method to determine VOCs in air. They found that analytes could be detected at the part per trillion (ppt) to sub part per billion (ppb) concentration levels when GC equipped with an ion trap mass spectrometric detector was used. The precision of the method was $1.5-6 \%$ relative standard deviation (RSD). The authors claim that the combination of SPME with canister sampling has clear advantages over conventional canister sampling methods.

The aim of this work was to develop SPME-GC-MS methodology of volatile organic pollutants determination in different gaseous samples. Being an equilibrium method SPME requires careful calibration. To calibrate the system standard gaseous mixtures were subjected to the complete analytical procedure (from sampling to final analysis) used for real samples. Partition coefficients of volatile organics between the fiber and air depend on temperature and humidity. The effect of these parameters on SPME-GC-MS response was studied.

\section{Experimental}

\section{Reagents and materials}

$n$-Decane (pure) was obtained from Merck (Germany); carbon tetrachloride, chlorobenzene, toluene and $p$-xylene (all reagent grade) and potassium acetate and potassium nitrate (both pure grade) were all from Polskie Odczynniki Chemiczne (Poland). Activated charcoal (40 - 60 mesh) was from Zaklady Suchej Destylacji Drewna (Poland). PTFE foils of 50, 120 and $220 \mu \mathrm{m}$ thickness (Du Pont, USA) were used for permeation membranes. 


\section{Apparatus}

The apparatus for dynamic generation of gaseous standard mixtures with stop flow facilities used in this work (Fig. 1) is a modification of the apparatus described elsewhere [10]. It is equipped with two thermostated gas washers (3 in Fig. 1) containing saturated aqueous salt solutions. By salt selection the required humidity can be given to a standard gas mixture. When kept at a temperature of $20{ }^{\circ} \mathrm{C}$, saturated potassium acetate gives a relative humidity $(\mathrm{RH})$ of $20 \%$ and saturated potassium nitrate solution gives a $\mathrm{RH}$ of $92 \%$. For dry air measurements, humidifying washers (3) are removed and a drier packed with molecular sieve 5A is installed between purifier (1) and generators (2). Drying adsorbent was regenerated periodically by baking at $360{ }^{\circ} \mathrm{C}$ for $24 \mathrm{~h}$.

For chromatographic analysis a Fisons GC-8000 gas chromatograph coupled with a Fisons MD-800 quadrupole mass spectrometer was used. GC-MS parameters were the same as given in an earlier paper [10]. An SPME holder for manual injection with a fused silica fiber coated with a $100 \mu \mathrm{m}$ polydimethylsiloxane film was from Supelco (Bellefonte, PA, USA). Sampled analytes were desorbed from the fiber in an injection port of $\mathrm{GC}$ at a temperature of $250{ }^{\circ} \mathrm{C}$ for $40 \mathrm{~s}$.

\section{Results and discussion}

Determination of organic compounds in air as in any other matrix with use of SPME requires calibration. Subjecting a standard gaseous mixture to the analytical procedure (from sampling to final analysis) used for a real sample seems the best calibration approach in this case.

SPME based GC methods consist of the two following steps:

1) extraction: The analytes are absorbed in a stationary phase coated on an SPME fiber (exposition),

2) injection: The analytes are thermally desorbed from the fiber and transferred to a chromatographic column.

Recovery of the analytes sorbed on the fiber (the second step) depends on the desorption time and the temperature of the injection port of the gas chromatograph. These parameters were determined in the previous studies [10]. The desorption temperature applied $\left(250{ }^{\circ} \mathrm{C}\right)$ was within a $200-$ $270{ }^{\circ} \mathrm{C}$ recommended range and below a $280{ }^{\circ} \mathrm{C}$ maximum working temperature given by the manufacturer (Supelco, Bellefonte, USA). At $250{ }^{\circ} \mathrm{C}$ all the analytes of interest were quantitatively transferred from the fiber to the $\mathrm{GC}$ column in $40 \mathrm{~s}$.

In an SPME based methodology, the sample analyte concentration is derived from the analyte amount absorbed in the fiber stationary phase. The most often used and reliable approach is based on the fiber exposition until equilibrium is reached. Partition coefficients determining the amount of an analyte sorbed by the fiber from a given matrix depend on the nature of the analyte and on the nature of the stationary phase and also on some experimental parameters. For the air matrices the temperature and the humidity should be the most important parameters. They can influence partitioning of the analytes between the sample and the fiber and can also affect the equilibration time.

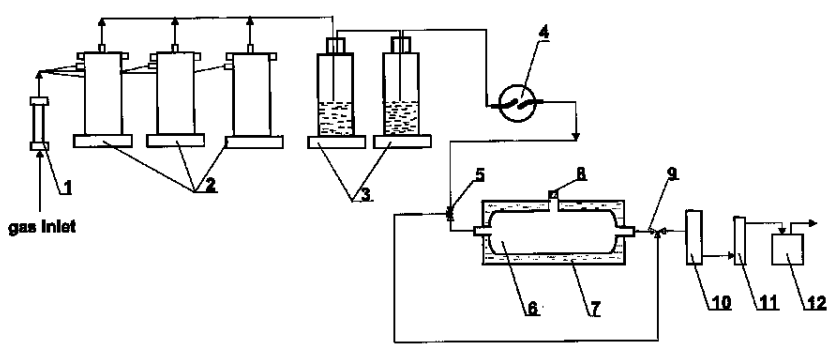

Fig. 1. The apparatus for generation of gaseous standard mixtures : 1-purifier, 2-generators, 3-thermostated glass washers, 4-pre-mixing chamber, 5-PTFE 3-way valve, 6-thermostated mixing glass chamber, 7-water of controlled temperature, 8-septum, 9-3-way glass valve, 10-flowmeter, 11-rotameter, 12-suction pump.

Studies of the temperature and humidity effects on the analytes sorption on the SPME fiber were preceded by establishing the extraction time (the fiber exposition time in the sample). This is based on the time determination to reach the equilibrium between the analyte concentration in the sample and the fiber stationary phase.

In table I equilibration times at different humidities, temperatures and analytes concentrations in the standard gaseous mixtures for the analytes studied are given.

The equilibration time is determined by plotting the detector signal versus the time of fiber exposition in a standard gaseous mixture. Examples of plots for toluene at two different relative humidities and for $n$-decane at two different temperatures are given in figure 2.

The equilibration time for toluene increases by c.a. $1 \mathrm{~min}$ with increasing the relative humidity from 0 to $20 \%$ (Fig. 2 and Tab. I) and by less than $1 \mathrm{~min}$ on further increasing the

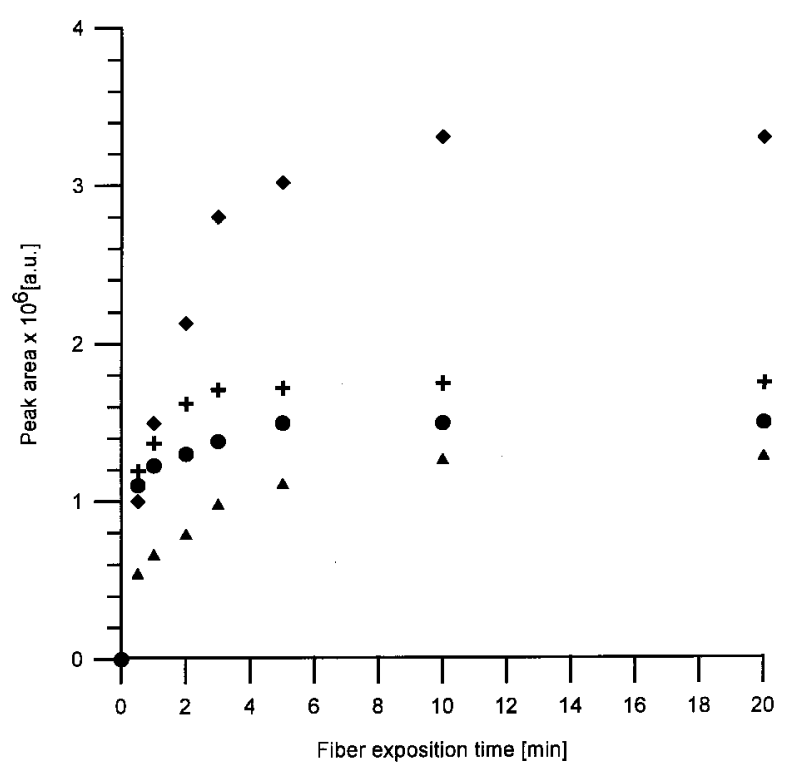

Fig. 2. Examples of extraction time profiles at different temperatures and relative humidities: + toluene $\left(c=0.62 \mathrm{mg} \mathrm{m}^{-3}, R H=\right.$ $\left.0 \%, T=20{ }^{\circ} \mathrm{C}\right), \bullet$ toluene $\left(c=0.62 \mathrm{mg} \mathrm{m}^{-3}, R H=20 \%, T=\right.$ $\left.20{ }^{\circ} \mathrm{C}\right), \diamond n$-decane $\left(c=0.14 \mathrm{mg} \mathrm{m}{ }^{-3}, T=20{ }^{\circ} \mathrm{C}, R H=0 \%\right), \boldsymbol{\Delta}$ $n$-decane $\left(c=0.14 \mathrm{mg} \mathrm{m}^{-3}, T=25^{\circ} \mathrm{C}, R H=0 \%\right)$. 


\section{Original articles}

Table I. Equilibration times at different analytes concentrations.

\begin{tabular}{|c|c|c|c|c|c|c|c|c|c|c|c|}
\hline \multirow{3}{*}{$\begin{array}{l}\text { Relative } \\
\text { humidity } \\
\text { RH[\%] }\end{array}$} & \multirow{3}{*}{$\begin{array}{c}\text { Temperature } \\
T\left[{ }^{\circ} \mathrm{C}\right]\end{array}$} & \multicolumn{10}{|c|}{ Equilibration time $t_{e q}[\mathrm{~min}]$ (concentration $c\left[\mathrm{mg} \mathrm{m}^{-3}\right]$} \\
\hline & & \multicolumn{2}{|c|}{$\begin{array}{c}\text { Carbon } \\
\text { tetrachloride }\end{array}$} & \multicolumn{2}{|c|}{ Toluene } & \multicolumn{2}{|c|}{ Chlorobenzene } & \multicolumn{2}{|c|}{ p-Xylene } & \multicolumn{2}{|c|}{ n-Decane } \\
\hline & & $t_{e q}$ & $C$ & $t_{e q}$ & $C$ & $t_{e q}$ & $C$ & $t_{e q}$ & $C$ & $t_{e q}$ & $C$ \\
\hline \multirow[t]{6}{*}{0} & 20 & 1.0 & 4.00 & 2.0 & 0.42 & 1.5 & 2.55 & 2.0 & 0.23 & 3.0 & 0.093 \\
\hline & & 2.0 & 6.01 & 2.5 & 0.62 & 2.0 & 3.85 & 2.0 & 0.34 & 5.5 & 0.14 \\
\hline & & 2.0 & 12.02 & 2.0 & 1.25 & 2.0 & 7.65 & 3.0 & 0.69 & 4.0 & 0.28 \\
\hline & 25 & 1.0 & 4.00 & 1.5 & 0.42 & 1.5 & 2.55 & 2.0 & 0.23 & 2.5 & 0.093 \\
\hline & & 2.0 & 6.01 & 2.0 & 0.62 & 2.0 & 3.82 & 2.0 & 0.34 & 3.0 & 0.14 \\
\hline & & 2.5 & 12.05 & 2.5 & 1.25 & 2.0 & 7.65 & 2.5 & 0.69 & 4.5 & 0.28 \\
\hline \multirow[t]{9}{*}{20} & 15 & 2.0 & 3.77 & 1.5 & 0.39 & 2.0 & 2.38 & 2.5 & 0.23 & 4.0 & 0.064 \\
\hline & & 2.0 & 5.66 & 2.5 & 0.59 & 2.0 & 3.58 & 2.5 & 0.34 & 4.5 & 0.095 \\
\hline & & 2.5 & 11.32 & 3.0 & 1.19 & 2.0 & 7.16 & 3.0 & 0.68 & 5.0 & 0.19 \\
\hline & 20 & 1.5 & 4.00 & 3.5 & 0.42 & 1.5 & 2.55 & 2.0 & 0.23 & 3.5 & 0.093 \\
\hline & & 2.5 & 6.01 & 4.0 & 0.62 & 2.0 & 3.82 & 2.0 & 0.34 & 5.5 & 0.14 \\
\hline & & 2.0 & 12.02 & 4.0 & 1.25 & 2.5 & 7.62 & 3.5 & 0.69 & 4.5 & 0.28 \\
\hline & 25 & 1.5 & 4.00 & 2.0 & 0.42 & 2.0 & 2.55 & 2.5 & 0.23 & 3.0 & 0.093 \\
\hline & & 2.5 & 6.01 & 3.0 & 0.62 & 2.5 & 3.82 & 2.0 & 0.34 & 3.0 & 0.14 \\
\hline & & 2.5 & 12.02 & 3.0 & 1.25 & 2.5 & 7.62 & 2.5 & 0.69 & 4.5 & 0.28 \\
\hline \multirow[t]{6}{*}{92} & 15 & 2.5 & 3.6 & 1.5 & 0.43 & 2.5 & 2.11 & 3.0 & 0.23 & 4.5 & 0.097 \\
\hline & & 2.5 & 5.4 & 2.5 & 0.64 & 2.5 & 3.16 & 3.0 & 0.34 & 5.0 & 0.14 \\
\hline & & 3.0 & 10.8 & 3.5 & 1.29 & 2.5 & 6.32 & 3.0 & 0.69 & 6.0 & 0.29 \\
\hline & 20 & 2.5 & 3.6 & 4.0 & 0.43 & 2.0 & 2.11 & 2.5 & 0.23 & 4.0 & 0.097 \\
\hline & & 3.0 & 5.4 & 4.0 & 0.64 & 3.0 & 3.16 & 3.0 & 0.34 & 6.5 & 0.14 \\
\hline & & 2.5 & 10.8 & 4.0 & 1.29 & 3.0 & 6.32 & 3.5 & 0.69 & 5.5 & 0.29 \\
\hline
\end{tabular}

humidity to $92 \%$ (Tab. I). The temperature increase from 20 to $25^{\circ} \mathrm{C}$ at $R H=0$ does not have a statistically significant effect on the equilibration time for $n$-decane (Tab. I). For the most unfavourable situation in our studies the equilibration time ranged from c.a. 2 min for the most volatile analyte $\left(\mathrm{CCl}_{4}\right)$ to c.a. $10 \mathrm{~min}$ for the least volatile analyte (n-decane). In case that some additional equilibration time lengthening factors could occur an extraction time of 15 min was fixed for further experiments.

\section{Effect of humidity on analyte amount sorbed on a fiber (partition coefficients)}

Effect of humidity on the analyte sorption on the SPME fiber was studied with use of earlier designed and constructed apparatus for generation of gaseous standard mixtures, additionally equipped with gas washers for controlling humidity of gaseous mixtures (Fig. 1). Washers are filled with saturated solutions of either potassium acetate or potassium nitrate which, at a temperature of $20^{\circ} \mathrm{C}$, give constant relative humidities of 20 and $92 \%$, respectively.

Effect of relative humidity on the sorption of analytes from mixtures at different analyte concentrations was studied for temperatures of 15,20 and $25{ }^{\circ} \mathrm{C}$. The effect of humidity at a temperature of $20{ }^{\circ} \mathrm{C}$ on analytes sorption is plotted in figure 3 . The sorption on the SPME fiber coated with PDMS at a temperature of $20{ }^{\circ} \mathrm{C}$ decreases by ca $30 \%$ for $\mathrm{CCl}_{4}$ and $n$-decane and ca $60 \%$ for toluene and $p$-xylene and ca $70 \%$ for chlorobenzene in the whole concentration range when $\mathrm{RH}$ increases from $0 \%$ (dry air) to $92 \%$. For temperatures of 15 and $25{ }^{\circ} \mathrm{C}$ similar decrease in the analytes sorption is observed.
The above results are consistent with those obtained by Chai et al. [7], who have observed $49 \%$ decrease (on average) in the analytes sorption at $25{ }^{\circ} \mathrm{C}$ when $\mathrm{RH}$ increased from zero (dry air) to $75 \%$. Quite recently Martos et al. [10] have observed only ca $10-18 \%$ drop at a temperature of $37{ }^{\circ} \mathrm{C}$, when $\mathrm{RH}$ increased from zero to $95 \%$. The

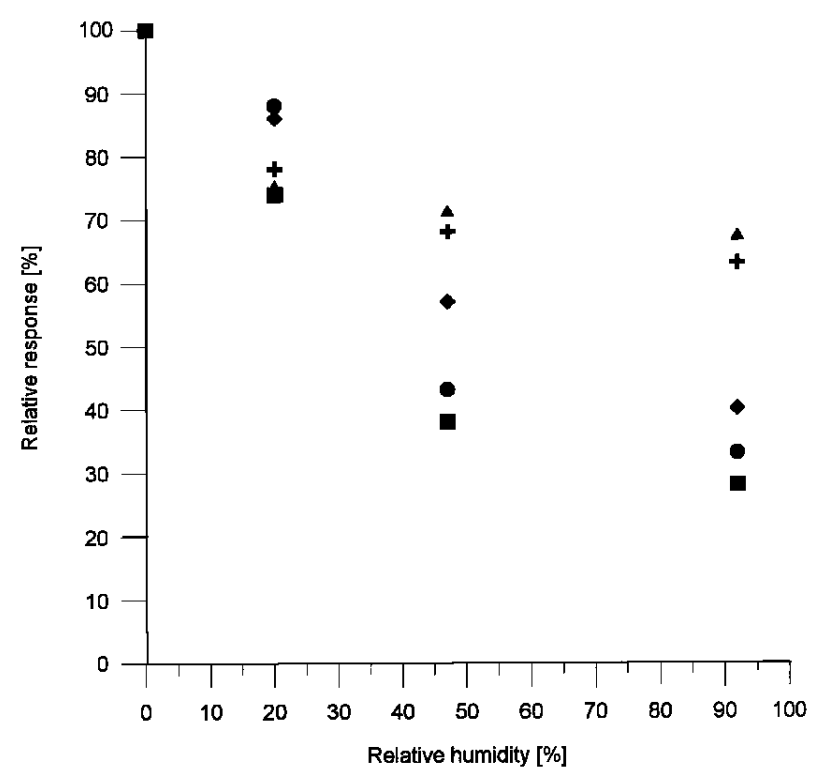

Fig. 3. Effects of relative humidity at $20{ }^{\circ} \mathrm{C}$ on analyte sorption ( chlorobenzene $-3.70 \mathrm{mg} \mathrm{m}^{-3}, \boldsymbol{\Delta} n$-decane $-0.12 \mathrm{mg} \mathrm{m}^{-3}$, 0 xylene $-0.34 \mathrm{mg} \mathrm{m}^{-3}, \bullet$ toluene $-0.61 \mathrm{mg} \mathrm{m}^{-3}$, + carbon tetrachloride $-5.83 \mathrm{mg} \mathrm{m}^{-3}$ ). 
experimental results of experiments on humidity effects published up to now have concerned different temperatures and concentrations differing by 2-3 orders of magnitude; therefore they are difficult to compare directly.

\section{Effect of temperature on partition coefficients}

Partition coefficients of analytes between a stationary phase on the fiber and a gaseous phase is temperature dependent [11]. For a majority of cases absorption is an exothermic process and partition coefficients defined as a ratio of the concentration in a stationary phase and the gaseous phase decrease as temperature increases. The actual relationship is a function of the stationary phase and the analyte.

In figure 4 , the effect of the extraction temperature on the analyte sorption at a relative humidity of $20 \%$ is presented. Measurements were made for temperatures of 15, 20 and $25{ }^{\circ} \mathrm{C}$ controlled with an accuracy of $\pm 0.2{ }^{\circ} \mathrm{C}$. The increase in temperature by $10{ }^{\circ} \mathrm{C}$ (from $15^{\circ} \mathrm{C}$ to $25^{\circ} \mathrm{C}$ ) at $R H=$ $20 \%$ decreases the amount sorbed by c.a. $15 \%$ for chlorobenzene, c.a. $30 \%$ for $n$-decane, by c.a. $40 \%$ for carbon tetrachloride and $56 \%$ for toluene and $p$-xylene. Similar changes were observed for $R H=0 \%$ and $R H=92 \%$. The decrease in partition coefficients was independent of analyte concentration in the gaseous mixture.

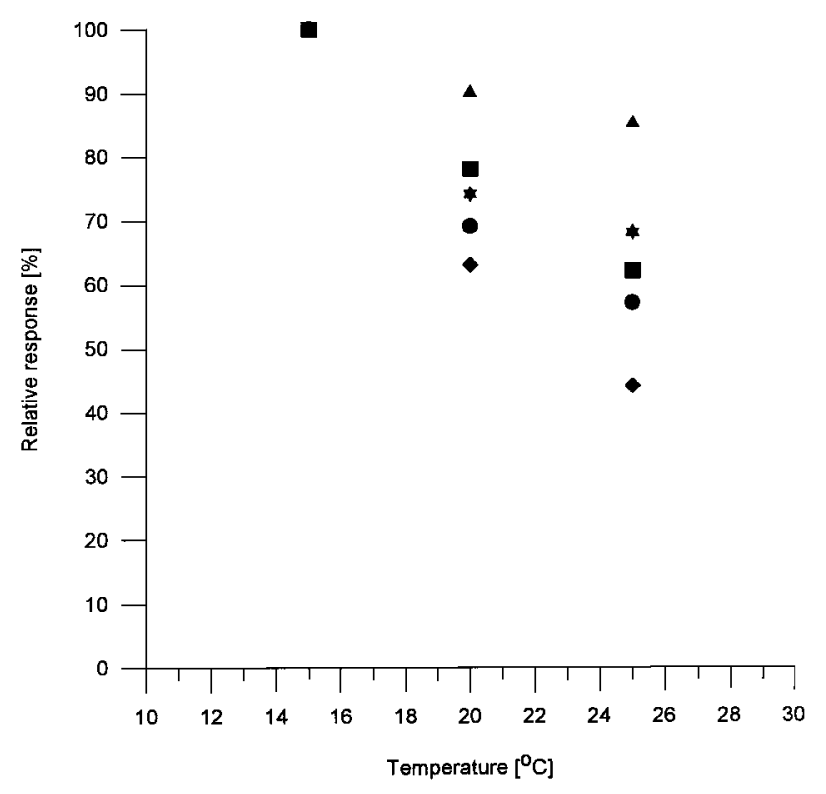

Fig. 4. Effects of temperature at a relative humidity of $20 \%$ on analyte sorption $\left(\boldsymbol{\Delta}\right.$ chlorobenzene $-3.70 \mathrm{mg} \mathrm{m}^{-3}, \star n$-decane -0.12 $\mathrm{mg} \mathrm{m}^{-3}, \boldsymbol{0}$-xylene $-0.34 \mathrm{mg} \mathrm{m}^{-3}, \boldsymbol{\square}$ toluene $-0.61 \mathrm{mg} \mathrm{m}^{-3}$, carbon tetrachloride $-5.83 \mathrm{mg} \mathrm{m}^{-3}$ ).

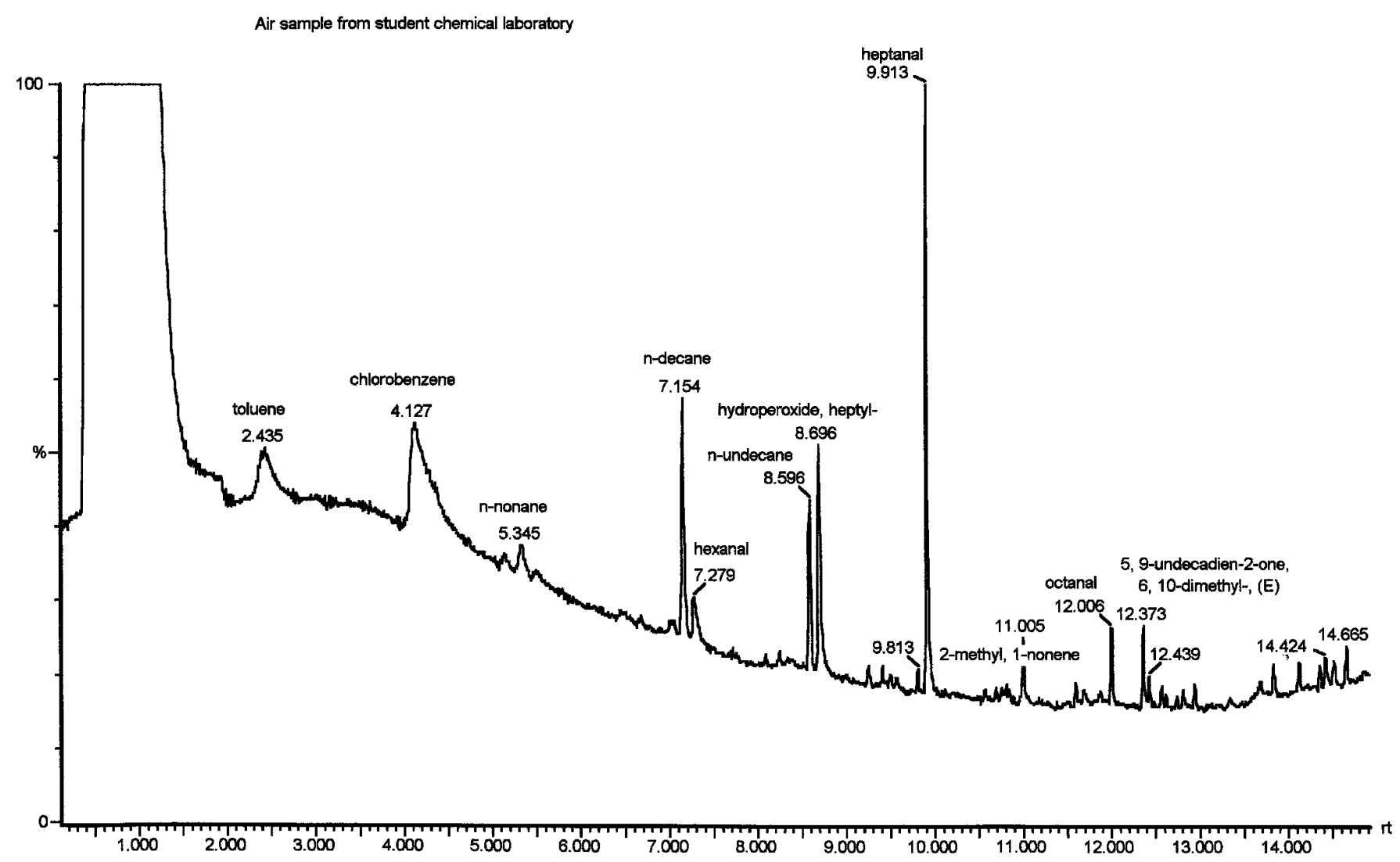

Fig. 5. An example of chromatogram of SPME sampled analytes from a students chemical laboratory. Chromatographic conditions: analytical column: DB $5 \mathrm{MS} 30 \mathrm{~m} \times 0.32 \mathrm{~mm}$ I.D. $\times 0.25 \mu \mathrm{m} d_{\mathrm{f}}$ (RESTEC, Bellefonte, USA); temperature program : $40{ }^{\circ} \mathrm{C}-2 \mathrm{~min}-$ $5{ }^{\circ} \mathrm{C} \mathrm{min}{ }^{-1}, 50{ }^{\circ} \mathrm{C}-15{ }^{\circ} \mathrm{C} \min ^{-1}, 230{ }^{\circ} \mathrm{C}-10 \mathrm{~min}$; injection port: splitless, injection temperature: $250{ }^{\circ} \mathrm{C}$. MS conditions: Scan mode, El ionization $(70 \mathrm{eV})$, ion for quantitation: carbon tetrachloride -117 , toluene -91 , chlorobenzene $-112, p$-xylene $-91, n$-decane 142 . 
Due to the relatively high decrease in the amount of the analytes sorbed with the $10{ }^{\circ} \mathrm{C}$ increase in temperature, sampling temperature should be known with an accuracy better than $0.5^{\circ} \mathrm{C}$.

\section{Analysis of real samples}

For accurate analysis, temperature and humidity of sampled gases should be measured. Once this is the case analyte concentration determination can be based on comparison of GC peak areas for the sample and for the standard gaseous mixture. With use of the apparatus shown in figure 1 the temperature of the standard gaseous mixtures (Fig. 1) can easily be controlled and the mixture can be humidified to a known level. For calibration, the temperature of the standard mixture is adjusted to that of the analysed samples. The washers with a solution giving a known relative humidity lower than that of the sampled air are installed. The SPME fiber is exposed to the standard mixture for a predetermined time (15 $\mathrm{min})$ and the analytes sorbed are analysed by GCMS. The identical measurement are made for the standard mixture with the humidity higher than that of the sampled air. The peak area is linearly interpolated to the humidity of the sampled air. Since the partition coefficients are not concentration dependent the standard mixture of any analytes concentrations can be used for calibration provided that they are precisely known. From the data obtained the analytes concentration in the samples studied are calculated.

Selected organic micropollutants in a student chemical laboratory were determined. Figure 5 presents an example of a chromatogram obtained. Parameters of the analysis were as follows: sampling time $=15 \mathrm{~min}$, air temperature $=$ $24.5{ }^{\circ} \mathrm{C}$, relative humidity $=54 \%$. In the sampled air toluene, chlorobenzene, $n$-nonane, $n$-decane, hexanal, $n$ undecane, hydroperoxide-heptyl, heptanal, 2-methyl-1- nonene, octanal and 5,9-undecadien-2-one, 6,10-dimethyl-, (E) were identified.

The methodology based on SPME is simpler and faster than that based on analyte trapping in tubes packed with solid sorbents (e.g. Tenax, Carbowax, activated charcoal, etc.). SPME sampling does not require additional equipment such as pumps, rotameters, aspirators, etc. SPME field application is quite easy and fast; therefore organic micropollutants can be sampled and determined on a large scale in indoor air, and also in atmospheric air in the vicinity of chemical plants, motorways and other roads.

\section{References}

1. Namieśnik, J.; Zygmunt, B.; Kozdroñ-Zabiegała, B. Pol. J. Environ. Stud. 1990, 3(4), 5-19.

2. Namieśnik, J. Chem. Anal. (Warsaw) 1997, 42, 487-495.

3. Zhang, Z.; Yang, M. J.; Pawliszyn, J. Anal. Chem. 1994, 66, 844 A-853A.

4. Boyd-Boland, A. A.; Chai, M.; Luo, Y. Z.; Zhang, Z.; Yang, M. J.; Pawliszyn, J.; Górecki, T. Environ. Sci. Technol. 1994, 28, 569-574.

5. Eisert, R.; Levsen, K. J. Chromatogr. 1996, 733, 143-157.

6. Gorlo, D.; Namieśnik, J.; Zygmunt, B. Chem. Anal. (Warsaw) 1997, 42, 297-314.

7. Chai, M.; Arthur, C. L.; Pawliszyn, J.; Belardi, R. P.; Pratt, K. F. Analyst. 1993, 118, 1501-1505.

8. Mangani, F.; Cenciarini, R. Chromatographia 1995, 41, 678684.

9. Chai, M.; Pawliszyn, J. Environ. Sci. Technol. 1995, 29, 693701 .

10. Gorlo, D.; Wolska, L.; Zygmunt, B.; Namieśnik, J. Talanta 1997, 44, 1543-1550.

11. Martos, P. A.; Pawliszyn, J. Anal. Chem. 1997, 69, 206-215.

12. Arthur, C. L.; Killam, L. M.; Buchholz, K. D.; Pawliszyn, J.; Berg, J. R. Anal. Chem. 1992, 64, 1960-1966. 